\title{
DIAGNÓSTICO AMBIENTAL DE RUAS E BAIRROS DA CIDADE DE TEIXEIRA, PB ${ }^{1}$
}

\author{
João Batista Alves²; Jacob Silva Souto²; Werlaneide A. da Silva ${ }^{3}$; Luzia Inês lopes ${ }^{3}$, Cícera Raquel F. \\ Rodrigues $^{3}$
}

\begin{abstract}
Resumo - O presente trabalho teve como objetivo caracterizar o ambiente de Teixeira, PB, analisando-se os impactos ambientais observados na cidade. A metodologia constou de visitas a todas as ruas, momento em que foram registrados os problemas ambientais. Em seguida, definiram-se os percentuais de cada parâmetro averiguado e priorizados pela metodologia de "Pareto". As análises dos dados indicaram, em ordem decrescente de ocorrências, os problemas ambientais, que foram: terrenos baldios; esgotos a céu aberto; entulho; lixo doméstico em terrenos baldios, lixos diversos (exceto os domésticos); lixo doméstico na rua; ruas e calçadas servindo de depósito para material de construção; e edificações deterioradas.
\end{abstract}

Palavras-chave: Cidade, meio ambiente, diagnóstico.

\section{ENVIRONMENTAL DIAGNOSIS OF TEIXEIRA'S STREETS AND NEIGHBORHOOD}

\begin{abstract}
The objective of this study was to characterize the environmental impacts observed in Teixeira, PB. All urban streets, paths and alleys of this small town in MidSouth Paraíba were visited and the environmental problems were recorded. The percentage of each parameter studied was estimated by the Pareto's methodology. Data analyses revealed, in decreasing order of incidence, the following environmental problems: waste grounds, open air sewers, construction waste, domestic and other discarded materials thrown away in waste grounds, domestic waste on the street, construction waste left on streets and sidewalks, and deteriorated buildings.
\end{abstract}

Key words: city, environment, diagnosis.

\section{INTRODUÇÃO}

A sociedade humana destaca-se pela capacidade de unir esforços e agregar-se social e economicamente ao redor de sistemas produtivos, o que possibilitou, ao longo da sua evolução, a formação de aglomerados humanos conhecidos como cidades, do latim "civitas".
A partir da formação desses aglomerados começam a surgir problemas de natureza ambiental, advindos das atividades produtivas, residenciais e sociais dos seres humanos. Estes problemas existem desde o surgimento do homem primitivo, quando ele começou a desenvolver técnicas, como o uso do fogo, da pecuária e da agricultura Dorst (1973), que relatou ainda a história das ações antrópicas ao longo dos milênios

\footnotetext{
${ }^{1}$ Recebido para publicação em 01.9.2003 e aceito para publicação em 10.8.2004.

${ }^{2}$ Departamento de Engenharia Florestal CSTR/UFCG, BR 110, B. Jatobá, Cx 64, CEP 58700 070, Patos-PB. Fone (083) 421-3397 (R. 235), Fax (083) 421-4659. E-mail: . E-mail: alvesjb@uol.com.br

${ }^{3}$ CSTR/UFCG. Patos-PB.
} 
e suas consequiências para a natureza. Chaffun (1997) mencinou que é nas cidades onde se concentra a maior parte das atividades econômicas, onde se consome a maioria dos recursos e onde se gera maior parte da poluição. Segundo o CEMPRE (2000), as cidades acumulam riquezas .... Entretanto, são também imensas consumidoras de recursos naturais..., e geram significativas quantidades de lixo que precisam ser dispostas de maneira segura e sustentável.

Douglas (1983), em estudo sobre o ambiente urbano, enfatizou os problemas relacionados a economia, dependência de suprimentos e seus impactos, balanço de energia nas cidades, balanço hídrico, balanço de massas, geomorfologia das cidades, biogeografia das cidades, disposição de resíduos, gestão e planejamento. Citou ainda que a partir desses elementos se podem desenvolver ferramentas (gerenciais e tecnológicas) para reduzir os impactos ambientais e outras questões.

Aspectos relacionados com as questões ambientais foram abordados por inúmeros autores, a exemplo de Lombardo (1985), que estudou a formação de ilhas de calor como um dos problemas sérios que as grandes cidades enfrentam, principalmente na época de inverno. Por sua vez, Branco (1991) abordou, os principais problemas ambientais das cidades no que concerne à poluição, citando e ilustrando suas diversas formas, como: poluição das águas, do ar, do solo, visual etc. Corrêa (1995) expôs modelos de desenvolvimento das cidades, tendo como base a especulação imobiliária e o jogo de interesse das classes dominantes. Gilbert (1995) abordou a questão da flora e da fauna no ambiente urbano, relatando as relações, adaptações e sobrevivência dos animais, no ambiente urbano. Maglio (1995) também discutiu a questão da gestão urbana e da qualidade de vida, apresentando estudo de caso sobre os impactos ambientais na cidade de São Paulo e analisando o caso da bacia do Guarapiranga.

Alberti (1997), discorrendo sobre a sustentabilidade das cidades, afirmou que uma variedade de novas ferramentas tem sido adaptada para o desenvolvimento de vários campos das ciências (antropologia, economia, geografia, biologia e sociologia). Tais ferramentas são: participação rural, contabilidade verde, estudos de impacto ambiental, SIG, indicadores ambientais, negócios e gestão (ISO 9000 E ISO 14000, educação ambiental e outros). Franco (2000), analisando o de- senvolvimento das cidades através de três estudos de casos, fez proposições a respeito do planejamento ambiental como ferramenta para a cidade sustentável. O tema da sustentabilidade pode ser encontrado nos estudos de Fiorillo (1997), Perlman (1997) e Wilheim (1997).

Apesar dos avanços nos países de primeiro mundo, no que concerne às questões ambientais, principalmente no ambiente urbano, e aos avanços nos estados da região Sul e Sudeste do Brasil, no Nordeste a maioria das ações realizadas se concentra nos impactos da seca e se esquece de que ela provoca o êxodo rural, e as pessoas migram para as cidades.

As pessoas sem preparo nenhum para a vida nas cidades provocam graves problemas socioeconômicos e ambientais, que vão interferir diretamente na sua qualidade de vida, principalmente na periferia das médias e grandes cidades.

Este trabalho teve como objetivos: realizar um estudo dos problemas ambientais de ruas e bairros da cidade de Teixeira, PB, a partir do conceito de "dossiê da ambiência" proposto por Rocha (1997); propor uma forma de levantamento e classificação de dados; e verificar se a metodologia proposta poderá ser reproduzida, para tal objetivo.

\section{METODOLOGIA}

De acordo com a Enciclopédia dos Municípios (IBGE, 1960), o município de Teixeira está localizado no sertão paraibano, em região de serra, altitude de $790 \mathrm{~m}$ em relação ao nível do mar, $7^{\circ} 13$ ' 13 ', de latitude sul e $37^{\circ} 15^{\prime} 15^{\prime \prime}$ de longitude W. Gr. A área do município é de $183 \mathrm{~km}^{2}$. O clima é quente e seco, com temperatura média variando de 15 a $28^{\circ} \mathrm{C}$ e pluviosidade média anual de 794,3 mm; o clima na classificação de Köppen é Aw' (BRASIL, 1972). A população do município era de 11.954 pessoas, composta por 5.787 homens e 6.167 mulheres, sendo 7.948 moradores urbanos e 4.006 da área rural (IBGE, 2001).

O diagnóstico ambiental da cidade de Teixeira, PB, foi baseado no "conceito" da metodologia preconizada por Rocha (1997), considerada como o "Dossiê de Ambiência", que representa um relato completo, através do registro de problemas ambientais observados ao percorrer vias urbanas e rurais de um município, visando ao meio onde vive a população (área urbana 
e área rural). No presente estudo, trabalhou-se com o ambiente urbano. Para a sua execução, adotaramse os seguintes procedimentos metodológicos:

\section{A - Reconhecimento da Área de Estudo, Observações e Definição de Parâmetros}

Esta fase constituiu-se de: avaliação geral da cidade, através de visita in loco de ruas representativas de todos os bairros; registro fotográfico; e anotação dos principais problemas ambientais observados, os quais foram: lixo doméstico na rua; animais domésticos; material de construção e entulho; esgoto a céu aberto; poluição visual; e edificações deterioradas, poluição atmosférica e arborização inadequada. Em seguida, levando em consideração a natureza (tipo de problema), intensidade e especificidade da incidência de cada parâmetro, estabeleceu-se uma classificação das diferentes formas de ocorrência de cada problema observado, utilizando planilha específica (Tabela 1), para o registro dos dados de campo.

\section{B - Diagnóstico Ambiental de Ruas e Bairros}

1- dividiu-se a cidade segundo seu espaço de ocupação em: centro, bairros intermediários e bairros periféricos.

A reambulação da área urbana consistiu em visitar todas as ruas da cidade (centro, bairros e vilas), analisar os problemas ambientais visíveis, fotografá-los e plotar os dados observados em planilha específica (Tabela 1).

Para a análise dos resultados foram utilizados métodos estatísticos simples, usando-se histograma; e para a priorização dos problemas em ordem de importância foi usada a análise de Pareto, uma ferramenta estatística empregada para se estabelecer a ordem em que as causas de determinados problemas ou perdas devem ser sanadas, conforme indicado pela metodologia proposta por Rocha (1997). Mais detalhes sobre priorização por Pareto em Oliveira (1996) e Vieira (1999).

\section{C - Entrevista com a População}

Foram entrevistadas 155 pessoas adultas e residentes nos diversos bairros da cidade. Foi solicitada a cada uma delas que citassem os três principais problemas ambientais da cidade, com o objetivo de verificar se a metodologia proposta e a visão dos moradores se concatenavam.

Tabela 1- Planilha de coleta de dados. Teixeira, PB. 2000

Table 1-Data collection form, Teixeira, PB. 2000

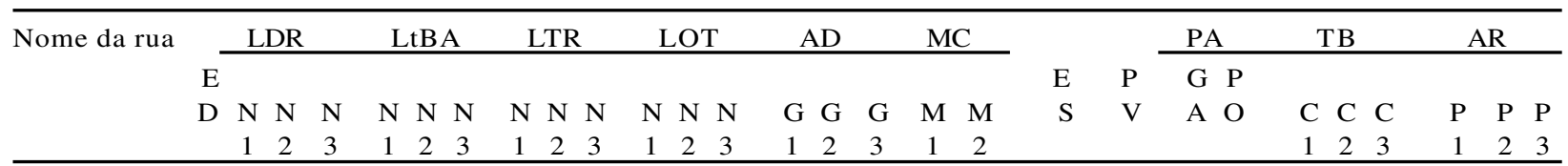

LEGENDA: LDR (presença de lixo doméstico na rua) - LtBA (lixo doméstico em terreno baldio) - LTR (lixo transbordado do recipiente de coleta) - LOT (móveis, madeira, fezes de animais, etc.) - AD (animais que perambulam pelas ruas sozinhos ou em grupos, revolvendo lixo etc.) - MC (restos de material de construção e material de comercialização na rua, como: deposição de madeira, ferro, cal, telha etc.) - ES (esgoto na rua) - PV (poluição visual, cartazes, outdoors e etc.) - PA (poluição atmosférica a partir de pontos localizados de poeira (PO), fumaça e outros gases visíveis (GA) - AR (condições da arborização) - TB (avaliado somente os terrenos abandonados, ou seja, sem cerca ou muro, com matagal e lixo). ED (edificação deteriorada - casa, prédio comercial em péssimas condições -, podendo ser de madeira, tijolos ou taipa - exemplos típicos: casa de favela e cortiços).

CLASSIFICAÇÃO A SER USADA: ANIMAIS: número de indivíduos - G1 (1 a 3) - G2 (4 a 6) e G3 (>6), espécies consideradas - (asinino, bovino, caprino, eqüino, suíno) - LIXO: N1 (concentrado), N2 (concentrado e espalhado nas proximidades), N3 (espalhado pela área). N1 foi definido como lixo concentrado, quando este se encontrava espalhado com no máximo $4 \mathrm{~m}^{2}$. N2 foi definido como lixo concentrado e espalhado nas proximidades, quando este se encontrava espalhado com um diâmetro ou forma desigual, mas que abrangesse uma área entre 4,1 e $10 \mathrm{~m}^{2}$. N3 foi definido como lixo espalhado, quando este se encontrava espalhado por uma área que abrangesse mais de $10 \mathrm{~m}^{2}$. ARBORIZAÇÃO: P1 (ausência), P2 (regular, não segue um padrão de espaçamento e, ou, tipo de árvore) e P3 (boa, segue um padrão de espaçamento e pelo menos algum tipo de árvore). TERRENO BALDIO ABANDONADO: $\mathrm{C} 1$ ( $<1$ ha), C2 (1,1 a 3 ha) e C3 ( $>3$ ha). MATERIAL DE CONSTRUÇÃO -M1: entulho e M2: material de comercialização. 


\section{RESULTADOS E DISCUSSÃO}

Os dados relativos ao número de incidências de cada parâmetro encontrado estão expressos na Figura 1.

Os resultados serão discutidos seguindo ordem de importância relativa, dados pela priorização dos problemas feita pela análise de Pareto, que estão expressos na Figura 2. Onze parâmetros foram responsáveis por $80 \%$ das incidências encontradas, portanto são nesses que se devem concentrar os esforços para uma futura solução dos problemas da cidade, pois a máxima de Pareto diz "poucos são vitais, a maioria é trivial”" (VIEIRA, 1999).

\subsection{Parâmetros Avaliados}

De todos os parâmetros e respectivas classes avaliados foram registradas 136 ocorrências.

\subsection{1 - Terrenos baldios}

Pela priorização de Pareto (Figura 2), observouse que o parâmetro que apresentou maior número de incidências - 15,7\% (Figura 1) foi o de Terrenos Baldios (TB - classe C1). Foram considerados terrenos baldios aqueles não cercados, abandonados com presença ou não de vegetação. Considerou-se terreno baldio como um problema ambiental, pelo fato de que a simples presença desse tipo de terreno, sem os devidos cuidados de limpeza com presença de vegetação, é um local onde podem estar presentes animais peçonhentos, insetos e roedores, o que já os tornam um problema de saúde pública e ambiental. Constituem também um ambiente potencialmente receptor de lixo doméstico, pois o hábito de jogar lixo em terreno baldio é comum nas cidades da região.

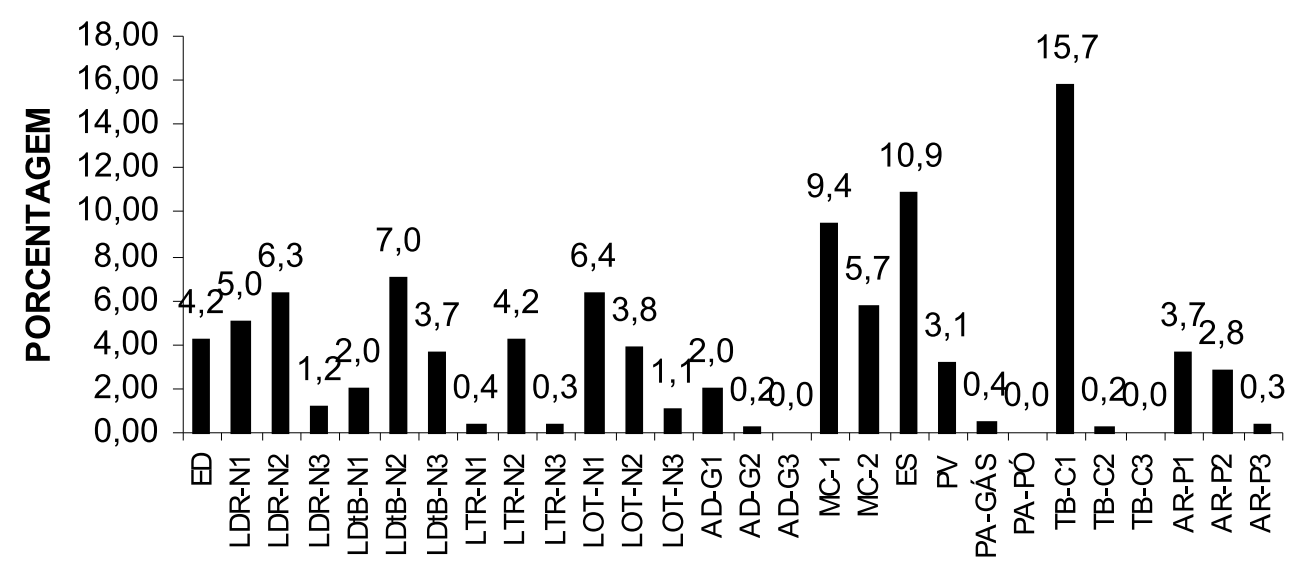

PARÂMETROS

Figura 1 - Resultados obtidos (percentual por parâmetro avaliado) do diagnóstico ambiental da cidade de Teixeira, PB em 2001.

Figure 1 - Results obtainned (percentage of each studied parameter) in Environmental diagnosis of Teixeira, PB, in 2001.

LEGENDA: ED - Edificação deteriorada; LDR - lixo doméstico na rua; LtBA (lixo doméstico em terreno baldio); LTR (lixo transbordado do recipiente de coleta), LOT (lixo outros: móveis, madeira, fezes de animais etc.); AD (animais domésticos); MC (restos de material de construção e material de comercialização na rua, como: deposição de madeira, ferro, cal, telha etc.); ES (esgoto na rua); PV (poluição visual); PA (poluição atmosférica: gás - gases e pó - poeiras); AR (condições da arborização); TB (terreno baldio abandonado); e AR (arborização).

CLASSIFICAÇÃO A SER USADA: ANIMAIS: número de indivíduos - G1 (1 a 3) - G2 (4 a 6) e G3 (>6), espécies consideradas - (asinino, bovino, caprino, eqüino, suíno) - LIXO: N1 (concentrado), N2 (concentrado e espalhado nas proximidades) e N3 (espalhado pela área). N1 foi definido como lixo concentrado, quando este se encontrava espalhado com no máximo $4 \mathrm{~m}^{2}$. N2 foi definido como lixo concentrado e espalhado nas proximidades, quando este se encontrava espalhado com um diâmetro ou forma desigual, mas que abrangesse uma área entre 4,1 e $10 \mathrm{~m}^{2}$; e N3 foi definido como lixo espalhado, quando este se encontrava espalhado por uma área que abrangesse mais de $10 \mathrm{~m}^{2}$. ARBORIZAÇÃO: P1 (ausência), P2 (regular, não segue um padrão de espaçamento e ou tipo de árvore) e P3 (boa, segue um padrão de espaçamento e pelo menos algum tipo de árvore). TERRENO BALDIO ABANDONADO: C1 (< 1 ha), C2 (1,1 a 3 ha) e C3 ( >3 ha). MATERIALDE CONSTRUÇÃO -M1: entulho e M2: material de comercialização. 


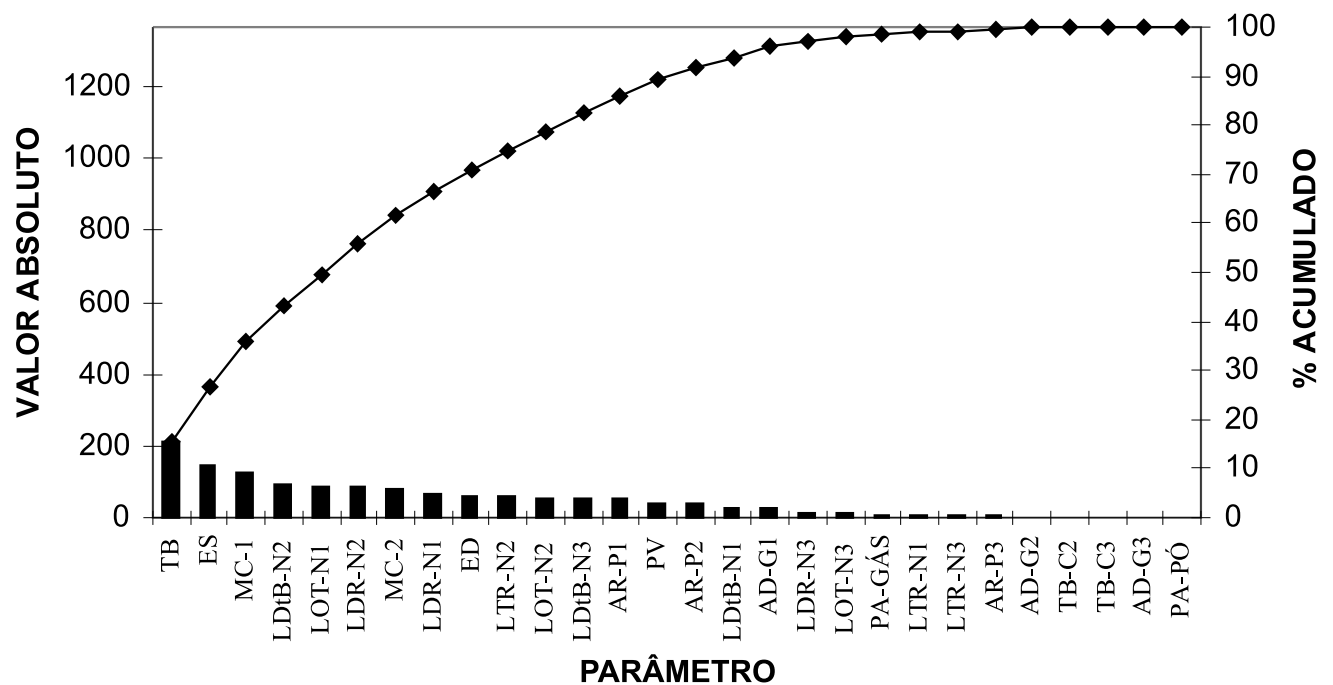

Figura 2 - Priorização por Pareto dos resultados de diagnóstico ambiental, da cidade de Teixeira, PB, em 2001.

Figure 2 - Priorization, by Paretos's methodology, of the results obtainned in the Environmental Diagnosis performed on Teixeira municiplality, PB, in 2001.

LEGENDA: ED (edificação deteriorada), LDR (lixo doméstico na rua), LtBA (lixo doméstico em terreno baldio), LTR (lixo transbordado do recipiente de coleta), LOT (lixo, outros: móveis, madeira, fezes de animais etc.), AD (animais domésticos.), MC (restos de material de construção e material de comercialização na rua, como: deposição de madeira, ferro, cal, telha etc.), ES (esgoto na rua), PV (poluição visual), PA (poluição atmosférica: gás - gases e pó - poeiras), AR (condições da arborização), TB (terreno baldio abandonado) e AR (arborização).

CLASSIFICAÇÃO A SER USADA: ANIMAIS: número de indivíduos - G1 (1 a 3), G2 (4 a 6) e G3 ( >6), espécies consideradas (asinino, bovino, caprino, eqüino, suíno) - LIXO: N1 (concentrado), N2 (concentrado e espalhado nas proximidades) e N3 (espalhado pela área). N1 foi definido como lixo concentrado, quando este se encontrava espalhado com no máximo $4 \mathrm{~m}^{2}$. N2 foi definido como lixo concentrado e espalhado nas proximidades, quando este se encontrava espalhado com um diâmetro ou forma desigual, mas que abrangesse uma área entre 4,1 e $10 \mathrm{~m}^{2}$. N3 foi definido como lixo espalhado, quando este se encontrava espalhado por uma área que abrangesse mais de $10 \mathrm{~m}^{2}$. ARBORIZAÇÃO: P1 (ausência), P2 (regular, não segue um padrão de espaçamento e, ou, tipo de árvore) e P3 (boa, segue um padrão de espaçamento e pelo menos algum tipo de árvore). TERRENO BALDIO ABANDONADO: C1 (<1 ha), C2 (1,1 a 3 ha) e C3 ( $>3$ ha).

MATERIAL DE CONSTRUÇÃO -M1: entulho e M2: material de comercialização.

Das 218 incidências registradas para esse parâmetro, $72,5 \%$ foram da classe $\mathrm{C} 1$. Da totalidade, o setor periférico da cidade foi o que apresentou maior porcentual de ocorrência $(73,4 \%)$, seguido pelos setores intermediário e centro com $17,4 \%$ e $9,2 \%$, respectivamente.

Esse aspecto é de fundamental importância no contexto da cidade de Teixeira, pois não havia regularidade de coleta de lixo por parte da prefeitura em todos os bairros da cidade. Com isso, os moradores da cidade, aproveitando-se dos terrenos baldios, faziam destes depósitos de lixo. Além do efeito visual negativo, torna-se propício à disseminação de doenças, multiplicação de animais nocivos como rato, animais peçonhentos e outros aspectos degradantes, do ponto de vista da saúde pública e do meio ambiente.

\subsubsection{Esgotamento sanitário}

O segundo maior problema ambiental detectado foi o dos Esgotos a Céu Aberto - ES (Figura 2), constituindo $10,9 \%$ (Figura 1) de um total de 149 incidências. Chama-se atenção para esse parâmetro pela sua importância em termos de saúde pública, pois existe o contato direto de pessoas, principalmente de crianças, com esses esgotos; efeito visual é negativo e impactador do meio ambiente. Além desses problemas, existem os odores insuportáveis e as águas residuárias altamente contaminadas, que podem infiltrar-se diretamente no solo, contaminando o len- 
çol freático, e os escoamentos superficiais formam sulcos, promovendo a erosão do solo e assoreando riachos e represas.

Existe maior número de incidências de esgoto a céu aberto no setor intermediário (42,3\% das incidências), seguido pelos setores periférico $(34,5 \%)$ e centro $(22,8 \%)$. Provavelmente, a incidência maior no setor intermediário se deve ao fato de que, no centro, a maioria das residências possuía ligações com a rede coletora e nos bairros periféricos as descargas corriam mais para os terrenos baldios ou canais, o que pôde ser confirmado ao se detectar que $73,5 \%$ e $66,7 \%$ dos terrenos baldios das categorias $\mathrm{C} 1$ e $\mathrm{C} 2$, respectivamente, estavam localizados na periferia.

Esse mesmo problema foi confirmado pela Secretaria de Meio Ambiente do Estado de São Paulo (SÃO PAULO,1998). No referido estado, o principal problema ambiental era a poluição das águas. Grippi (2001) salientou que os grandes poluidores de águas no Brasil são exatamente as prefeituras municipais, que deveriam estar tratando todo o esgoto da cidade antes de seu despejo. Maricato (1997) também mencionou que o esgoto doméstico é, atualmente, o maior poluidor dos recursos hídricos. O CEMPRE (2000) chamou a atenção para a necessidade urgente de se tomarem medidas para o tratamento dos esgotos sanitários e adoção de ações para o lixo, pois a maioria dos riachos e córregos que cortam as cidades brasileiras, sejam elas pequenas, médias ou grandes, já se encontram poluídos. No município de Patos, PB, vizinho de Teixeira, Melo (2001) citou que apenas $7,2 \%$ dos esgotos da cidade recebiam algum tipo de tratamento, sendo parte da coleta de esgoto feita pela rede pluvial.

Esses dados vêm reforçar o que Grippi (2001) afirmou, demonstrando a situação calamitosa do esgotamento sanitário nos municípios interioranos do país.

\subsubsection{Material de construção ou entulho}

O entulho - MC-1, com 129 incidências, foi responsável por 9,4\% das ocorrências (Figura 1). O setor que apresentou mais esse tipo de problema foi o periférico, com 51,94\% das incidências, seguido pelos setores do centro e intermediário, ambos com 24,03\%.

Durante o diagnóstico de campo, verificou-se um grande número de construções no setor periférico, o que comprova os números de maior incidência de entulhos nesse setor, pois o centro dispunha de poucos ter- renos para construção. O setor intermediário, que poderia ser um setor de construção, talvez não seja ocupado com tanta intensidade devido ao valor dos terrenos em relação aos da periferia, que são de custos mais baixos, na sua maioria. Provavelmente, os terrenos de periferia vêm sendo ocupados por pessoas de baixa renda, o que foi verificado pela qualidade das construções. Muitos desses proprietários procuravam a cidade para fixar suas residências, já que a cada dia se tornava mais difícil viver no meio rural.

Outra característica observada na cidade foi que os entulhos funcionavam como depósito de lixo, ou seja, quando se deixam restos de construção na rua, as pessoas começam a jogar lixo doméstico em cima, agravando ainda mais os problemas, tanto visuais, quanto de saúde pública, uma vez que esses locais vão servir de abrigo e proliferação de insetos e roedores.

Segundo o CEMPRE (2000), o entulho é o conjunto de fragmentos ou restos de tijolos, concreto, argamassa, aço, madeira etc. provenientes do desperdício na construção, reforma e, ou demolição de estruturas, com os prédios, residências e pontes. Na mesma citação, afirmou ainda que o entulho, quando descartado das construções, causa ônus devido ao seu volume, que pode chegar a $50 \%$ do volume ocupado em aterros públicos Além disso, sua destinação clandestina provoca problemas de saúde públicos, pela proliferação de insetos e roedores. Outros transtornos são citados, a saber: geração de depósitos instáveis, provocando deslizamentos quando lançados em encostas e obstrução do escoamento, provocando inundações quando lançados em terrenos baixos.

Lima (2001) mencionou que a média de perdas de material na construção civil, no mundo, é de $10 \%$; no Brasil, oscila entre 20 e $30 \%$. Citou, ainda, o exemplo de São José dos Campos, SP, onde o entulho corresponde a quase $65 \%$ do total de resíduos sólidos urbanos daquela cidade.

O material de construção categoria MC2 foi considerado como poluição visual, pelo seu grande número de incidências, em relação ao que tradicionalmente se considera como poluição visual (cartazes, outdoors etc.). Resolveu-se considerá-lo como tal, visto que, além de ser desagradável aos olhos do observador, provoca transtornos à população ao ocupar parte de ruas e calçadas.

O número de incidências dessa categoria foi de 
5,7\% (total de 78 ocorrências) no diagnóstico ambiental (Figura 1). Os setores que apresentaram maior porcentual de incidências foram o intermediário e o periférico, ambos com $44,9 \%$, seguidos pelo setor do centro, com $10,3 \%$ das incidências.

\subsubsection{Lixo}

Um dos maiores problemas ambientais da cidade de Teixeira era o lixo. Conforme mostrado nos parágrafos subseqüentes, a cidade produz, segundo dados oficiais, $2.500 \mathrm{~kg} / \mathrm{dia}$ (lixo coletado).

Observando a Figura 2, entre os 11 itens incluídos como prioritários pela metodologia de Pareto, podese comprovar que cinco sobre lixo estão inclusos. Somando os diversos parâmetros associados ao lixo, ter-se-á $28,9 \%$ das incidências (total de 395 ocorrências), distribuídos da seguinte forma: 7,0\%, 6,4\%, 6,3\%, $5,0 \%$ e $4,2 \%$ (Figura 1), com relação aos respectivos parâmetros avaliados: LDtB (Lixo Doméstico em Terreno Baldio - classe N2), LOT (Lixo Outros - classe - N1), LDR (Lixo Doméstico na Rua - classe - N2), LDR (Lixo Doméstico na Rua - classe - N1) e LTR (Lixo Doméstico Trasbordado de Recipientes - classe N2).

Seguindo a ordem decrescente do número de incidências, apresentar-se-á a situação de cada parâmetro, em cada um dos setores.

O parâmetro LDtB N2 (Lixo Doméstico em Terreno Baldio classe N2) teve $78,1 \%$ de suas incidências na periferia (total de 96 ocorrências), como era esperado, pelo fato de apresentar maior número de terrenos baldios, bem como carência de serviços de limpeza (aliada à falta de educação das pessoas residentes). O setor intermediário apresentou $14,6 \%$ das incidências e o centro, 7,3\%.

Em seguida tem-se o parâmetro LOT (Lixo Outros - classe N1), com um total de 87 ocorrências, sendo $43,7 \%$ destas no setor intermediário, $34,5 \%$ na periferia e $21,8 \%$ no centro. Previa-se que o setor que iria apresentar o maior número de incidências fosse o periférico, em qualquer das classes, o que não se observou nesta classe. Verificou-se a distribuição dos dados das outras classes, quanto a esse tipo de lixo, sendo notado que o setor periférico e o intermediário se igualavam na classe $\mathrm{N} 2$, e a periferia apresentava maior índice na classe N3. Esta classe significa grandes áreas ocupadas por lixo. Provavelmente, a falta ou a baixa coleta nos setores intermediários e periferia contri- buía para que se acumulasse e espalhasse este tipo de lixo. No dia-a-dia, constatou-se que, quando em determinado local, o lixo não é coletado, aquele pequeno montículo funcionava como um atrativo para se jogar mais lixo, e aí o acúmulo e espalhamento eram inevitáveis.

Em seguida, têm-se as duas classes (N1 e N2) de LDR (Lixo Doméstico na Rua), com incidência de 6,3 e 5,0\%, respectivamente (Figura 1). O total de ocorrências nas respectivas classes foi de 86 e 68 (total de 154); ambas com porcentuais de incidências bastante significativos no setor da periferia. Na classe $\mathrm{N} 1,51,5 \%$ das incidências estavam no setor da periferia, seguidas pelos setores intermediário e centro, com 30,9 e $17,6 \%$, respectivamente.

$\mathrm{Na}$ classe $\mathrm{N} 2,55,8 \%$ das incidências estavam na periferia, seguida também dos setores intermediário e centro, com 27,9 e $16,3 \%$, respectivamente. Na categoria N3, observou-se que $68,8 \%$ das incidências eram nos bairros periféricos. Os dados reforçam que, à medida que se afastava do centro, a coleta de lixo ficava muito aquém das necessidades da população.

Por último, tem-se LTR (Lixo Transbordado do Recipiente de Coleta - classe N2), com 4,2\% das incidências (Figura 1) e 58 ocorrências. Esse dado comprova mais uma vez a deficiência no sistema de coleta de lixo, pois, à medida que não havia coleta de lixo que atendia a demanda, depois de cheio, as pessoas começavam a jogar o lixo nas imediações do recipiente. Nesse parâmetro, observou-se que o centro era o mais atingido, com $46,6 \%$ das ocorrências, seguido pelos setores intermediário e periferia, com 36,2 e 17,2\%, respectivamente. Isso indica que no centro a falta de terrenos baldios fazia que as pessoas optassem ou tivessem a única opção de jogar o lixo próximo ao recipiente, já nos bairros mais periféricos, com a maior presença de terrenos baldios, elas optavam por jogar o lixo nesses locais.

A Prefeitura Municipal de Teixeira coletava lixos domiciliares, públicos, comerciais, hospitalares, agrícolas e entulhos, perfazendo um total de 2,5 toneladas/dia, com a seguinte composição básica: lixo orgânico, papel, vidro, metal, madeira e lixo hospitalar. Segundo dados daquele órgão, $95 \%$ do lixo domiciliar era coletado. O depósito era a céu aberto, sem nenhum tipo de controle, e localizava-se em área particular, sendo o lixo hospitalar recolhido e queimado no lixão.

R. Árvore, Viçosa-MG, v.28, n.5, p.755-764, 2004 
Segundo dados do SEBRAE (1997), a situação do destino do lixo das residências em Teixeira, era a seguinte: $37,92 \%$ jogados em terreno baldio; $5,10 \%$ coletados direta ou indiretamente; $1,68 \%$ queimado ou enterrado; e 55,30\% outros. Evidentemente, havia discordâncias de números, mas talvez fosse preferível confiar na resposta direta e atualizada da população. Segundo os dados do IBGE (1991a), a disposição dos resíduos sólidos urbanos nos municípios brasileiros é assim distribuída: $76 \%$ nos lixões, $13 \%$ nos aterros controlados, $10 \%$ no aterro sanitário e $1 \%$ na reciclagem. O IBGE (1991b), no estudo sobre dimensões das carências sociais (caderno da Paraíba), sinalizou que $38,8 \%$ dos domicílios da cidade de Teixeira possuíam saneamento (dentre estes a coleta de lixo) inadequado.Tais dados indicam a realidade encontrada pelo presente trabalho.

\subsubsection{Edificação deteriorada}

Por último, analisou-se o problema das edificações deterioradas. Apesar de aparecer entre os 11 parâmetros, com 4,2\% das incidências (Figura 1), avaliados dentro dos $80 \%$ da priorização por Pareto, o problema de edificação deteriorada em Teixeira é relativamente pequeno, se forem considerados os problemas que as grandes cidades têm com esse tipo de construção. Na realidade, esse problema em Teixeira está distribuído em diversas áreas da cidade, sem uma aglomeração mais significativa, a não ser em alguns becos antigos. Observou-se a ocorrência de 58 edificações deterioradas, sendo $43,10 \%$ das incidências localizadas no centro, seguidas dos setores intermediário e periférico, com 36,21 e 20,69\%, respectivamente. Eram construções velhas, sem a devida manutenção; algumas abandonadas.

O problema gerado por esse tipo de construção era mais de saúde pública do que ambiental, pois as paredes rachadas ou cheias de frestas poderam servir de moradia para insetos causadores de doenças, como barbeiros, baratas e outros animais como o rato. Outro problema a citar seria a possibilidade de essas edificações abrigarem marginais. Do ponto de vista ambiental, alguns tipos de construção, principalmente as abandonadas, serviam de depósito de lixo e sofriam riscos de desabamento, além de se apresentarem esteticamente desagradáveis (poluição visual), prejudicando o conjunto arquitetônico da cidade.

\subsection{Outros problemas ambientais observados}

Além desses problemas diagnosticados pela metodologia, havia outros preocupantes, a saber: lixão a céu aberto; falta de coleta e tratamento específicos de lixo hospitalar, que era depositado no lixão sem nenhum controle; poluição de açude público dentro da cidade; escassez de água tratada, fazendo com que a população usasse águas contaminadas; e leito de canais ocupados com cultura de gramíneas ou sendo usados para retirada de barro para confecção de tijolos, provocando destruição das margens e assoreamento dos leitos.

\subsection{Metodologia}

O método de trabalho proposto foi de fácil execução e demandou pouco tempo. Foram gastos seis dias para a atividade de campo e dois para análises, trabalhando-se com uma equipe de TRÊS pessoas. Os recursos financeiros gastos, entre material e pesso$\mathrm{al}$, foram em torno de $\mathrm{R} \$ 2.000,00$ (primeiro semestre de 2000).

Das entrevistas com a população, obtiveram-se os seguintes resultados: $43 \%$ delas citaram que o principal problema da cidade, em termos ambientais, era o lixo, $33,5 \%$ a questão dos esgotos, $16,1 \%$ animais nas ruas e $7,4 \%$ outros problemas.

Dessa forma, verificou-se que a metodologia apresentada pode realizar um diagnóstico mais técnico, registrando o nível de ocorrência, dar certa dimensão e priorizar os problemas ambientais do perímetro urbano. Além disso, pode-se verificar que o método proposto aproximava-se da mesma visão que os moradores tinham desses problemas.

Considerando os baixos custos de execução em termos financeiros e de tempo, as prefeituras de pequenas cidades podem utilizar tal recurso para monitorar a evolução dos problemas ambientais.

\section{CONCLUSÕES}

Os principais problemas ambientais encontrados, em ordem decrescente de importância, foram: terrenos baldios; esgotos a céu aberto; entulho; lixo doméstico em terrenos baldios, lixos diversos (exceto os domésticos); lixo doméstico na rua; ruas e calçadas servindo de depósito de material de construção; e edificações deterioradas. 
Outros problemas que impactavam negativamente a cidade eram: lixão a céu aberto, descarte do lixo hospitalar a céu aberto, canais e margens de canais deterioradas.

A metodologia aplicada foi adequada para os propósitos apresentados e pode ser utilizada para o diagnóstico de problemas ambientais em pequenas cidades, usando-se os mesmos parâmetros e classes, ou adaptada à realidade de cada local, mas conservando os mesmos princípios.

\section{REFERÊNCIAS BIBLIOGRÁFICAS}

\section{ALBERTI, M. Sustainability and urban environmental management: cidades sustentáveis. Teleconferência Worldnet. São Paulo: 1997. não paginado.}

BRANCO, S. M. Ecologia da cidade. São Paulo: Moderna,1991. 56p.

CHAFFUN, N. Dinâmica global e desafio urbano. In: BONDUKI, N. (Org.). Habitat: as práticas bem sucedidas em habitação, meio ambiente e gestão urbana nas cidade brasileiras. São Paulo: Studio Nobel, 1997. 267p.

CEMPRE. Lixo municipal: manual de gerenciamento intergrado. 2. ed. São Paulo: IPT/ CEMPRE, 2000. 370p.

CORRÊA, R. L. O espaço urbano. São Paulo: Ática, 1995. 94p.

DORST, J. Por uma ecologia política: antes que a natureza morra. Tradução Rita Buongermino. São Paulo: Edgard Blücher, 1973. 394p. Título original: Avant que naturmeure, pour une écologie politique.

DOUGLAS, I. The urban environment. London: Edward Arnold, 1983. 229p.

BRASIL: Ministério da Agricultura. Levantamento exploratório reconhecimento de solos do Estado da Paraíba. Rio de Janeiro: MA/EPE-SUDENE/DRN, 1972. $670 \mathrm{p}$.

FIORILLO, A. Misurale l'impronta ecològica delle città L'ésperienza italiana: cidades sustentáveis: Teleconferência Worldnet. São Paulo: 1997. não paginado.
FRANCO, M. A. R. Planejamento ambiental para a cidade sustentável. São Paulo: Annablume: FAPESP, 2000. 296p.

GILBERT, O. L. The ecology of urban habitats. 2. ed. London: Chapman \& Hall, 1995. $317 \mathrm{p}$.

GRIPPI, S. O líquido precioso e o descaso. Revista Banas Ambiental, v. 2, n. 12, p. 30-31, 2001.

IBGE. Enciclopédia dos Municípios Brasileiros. Rio de Janeiro: 1960.

IBGE. Censo demográfico da Paraíba. Rio de Janeiro, n. 13, 1991a. 259 p.

IBGE. Sinopse preliminar do censo demográfico: Paraíba, Rio de Janeiro, v. 6, n. 11, 1991b. p.1-75.

IBGE. Dimensões das Carências Sócias.

Informações Municipais, n. 15, p.1-122, 1991C.

IBGE. Resultados preliminares do censo 2000: Paraíba, Rio de Janeiro.Disponívelemhttp:// www.ibge.com.br/ibge/estatísticas/popu../ consulta.pnp acesso em: 25 jul. 2001.

LIMA, D. J. Gestão de resíduos sólidos urbanos no Brasil. Campina Grande: ABES, 2001.267p.

LOMBARDO, M. A. Ilha de calor nas metrópoles. São Paulo: Hucitec, 1985. 244p.

MAGLIO, I. C. Gestão urbana e qualidade de vida: um estudo de caso. In: TAUK-TORNISELO, S. M. et al. (Organizadores) Análise ambiental: estratégias e ações. São Paulo: T.A. Queiroz, 1995. $381 p$.

MARICATO, E. Contribuição para um plano de ação brasileiro. In: BONDUKI, N. (Org.).

Habitat: As práticas bem sucedidas em habitação, meio ambiente e gestão urbana nas cidade brasileiras. São Paulo: Studio Nobel, 1997. $267 p$.

R. Árvore, Viçosa-MG, v.28, n.5, p.755-764, 2004 
MELO, A. C. Uma abordagem sócioeconômica dos resíduos sólidos urbanos da cidade de Patos-PB. 2001. 133f. Dissertação (Mestrado em Agronomia) Universidade Federal de Pernambuco, Recife. 2001.

OLIVEIRA, S. T. Ferramentas para o aprimoramento da qualidade.

São Paulo: Pioneira, 1996. 115p. (Série: Qualidade Brasil).

PERLMAN, J. Sustainable cities and local-global linkages:cidades sustentáveis: Teleconferência Worldnet. São Paulo: 1997. Não paginado.
ROCHA, J. S. M. Manual de projetos ambientais. Santa Maria: Unviersidade Federal de Santa Maria, 1997. 423p.

SEBRAE (Paraíba). Teixeira. João Pessoa: SEBRAE-PB. 1997. 51p. (série: Diagnóstico Sócioeconômico).

SÃO PAULO. Secretária do Meio Ambiente de São Paulo. Aspectos ambientais e urbanos do Estado de São Paulo. São Paulo: 1998. 39p.

VIEIRA, S. Estatística para a qualidade. Rio de Janeiro: Campus, 1999. 98p.

WILHEIM, J. Cidades sustentáveis - utopia $\mathrm{x}$ metas. Cidades sustentáveis: Teleconferência Worldnet. São Paulo: 1997. Não paginado. 